\title{
Uma coletânea para alargar o olhar sobre a 'nova ordem (des)informativa na era da pós-verdade'
}

A collection to broaden our view of the 'new (dis)informative order in the post-truth era'

Una colección para ampliar nuestra visión del 'nuevo orden (des) informativo en la era de la post-verdad'

Taís Seibt ${ }^{1, a}$

tseibt@unisinos.br | https://orcid.org/o0oo-0002-2709-5658

1 Universidade do Vale do Rio dos Sinos (Unisinos), Escola da Indústria Criativa/Jornalismo. Porto Alegre, RS, Brasil.

a Doutorado em Comunicação e Informação pela Universidade Federal do Rio Grande do Sul (UFRGS). Porto Alegre, RS, Brasil.

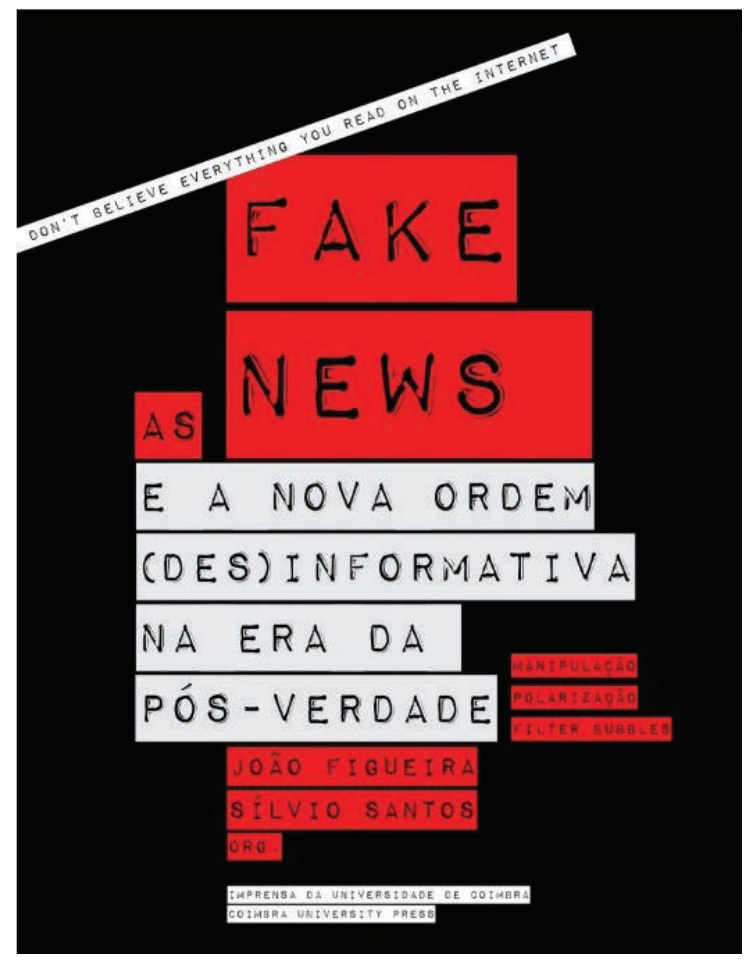




\section{Resumo}

Esta resenha apresenta as ideias centrais da coletânea As fake news e a nova ordem (des)informativa na era da pós-verdade, de João Figueira e Silvio Santos, publicada em 2019, que reúne 12 artigos sobre o fenômeno da desordem informacional e seus impactos na comunicação, na democracia e na prática do jornalismo. Partindo de diferentes perspectivas teóricas, os artigos traçam um panorama histórico da desinformação, buscando dimensionar o papel da tecnologia nesse processo. A análise da obra divide os textos em três eixos temáticos: a notícia e suas falsificações; o impacto das falsificações nos estados democráticos; e o discurso noticioso na desordem informacional.

Palavras-chave: Fake news; Desinformação; Desordem informacional; Pós-verdade; Comunicação.

\section{Abstract}

This review presents the central ideas of the collection of essays As fake news e a nova ordem (des) informativa na era da pós-verdade (The fake news and the new (dis)informative order in the post-truth era), by João Figueira and Silvio Santos (2019), which gathers 12 articles about the phenomenon of informational disorder and its impact on the communication, the democracy and on the journalism practices. Having as starting point different theoretical perspectives, the articles outline a historical panorama of disinformation, seeking to dimension the role of technology in this process. The analysis of the book divides the texts into three thematic axes: the news and its falsifications; the impact of the falsifications on democratic states; and the news discourse on the information disorder.

Keywords: Fake news; Disinformation; Informational disorder; Post-truth; Communication.

\section{Resumen}

Esta reseña presenta las ideas centrales de la colección As fake news e a nova ordem (des)informativa na era da pós-verdade (Las fake news y el nuevo orden (des)informativo en la era de la post-verdad), de João Figueira y Silvio Santos (2019), que reúne 12 artículos sobre el fenómeno del desorden informativo y sus impactos en la comunicación, la democracia y la práctica del periodismo. Partiendo de diferentes perspectivas teóricas, los artículos delinean un panorama histórico de la desinformación, buscando dimensionar el papel de la tecnología en este proceso. El análisis del libro divide los textos en tres ejes temáticos: las noticias y sus falsificaciones; el impacto de las falsificaciones en los estados democráticos; y el discurso de las noticias en el desorden informativo.

Palabras clave: Fake news; Desinformación; Desorden informativo; Post-verdad; Comunicación.

Declaração de conflito de interesses: não há.

Fontes de financiamento: não houve.

Considerações éticas: não há.

Agradecimentos/Contribuições adicionais: não há.

Histórico do artigo: submetido: 06 jan. 2020 | aceito: 26 jan. 2020 | publicado: 31 mar. 2020.

Apresentação anterior: não houve.

Licença CC BY-NC atribuição não comercial. Com essa licença é permitido acessar, baixar (download), copiar, imprimir, compartilhar, reutilizar e distribuir os artigos, desde que para uso não comercial e com a citação da fonte, conferindo os devidos créditos de autoria e menção à Reciis. Nesses casos, nenhuma permissão é necessária por parte dos autores ou dos editores. 


\section{A obra}

No texto de introdução da recém-publicada coletânea As fake news e a nova ordem (des)informativa na era da pós-verdade, João Figueira e Silvio Santos anunciam "um olhar alargado e diverso" voltado para o fenômeno da desinformação na perspectiva de "um importante conjunto de pesquisadores portugueses e brasileiros"1. A obra organizada pelos pesquisadores da Universidade de Coimbra não só oferece tal olhar como preenche grandiosamente uma lacuna que se apresentava para acadêmicos em busca de referências sobre o tema em língua portuguesa.

São 12 artigos com análises, reflexões e provocações para tensionar a chamada 'era da pós-verdade' a partir das mais variadas matrizes teóricas. A convicção de que a expressão que intitula a coletânea é frágil para aclarar o que abala o cenário midiático, social e político contemporâneo atravessa todos os textos. É propriamente no esforço de refutar a expressão 'fake news', cada vez mais vazia de sentido, que ganha relevo tal variedade de referenciais teóricos acionados por cada um dos autores. A começar pelo texto de apresentação, escrito por um dos arautos dos estudos de jornalismo no Brasil, Ciro Marcondes Filho, com o nada erudito título ‘O buraco é mais embaixo’.

Conhecido crítico dos princípios de objetividade e imparcialidade gestados no que chama de imprensa burguesa', Marcondes Filho argumenta que as fake news são uma nova forma de dominação, embora não sejam em si um fato novo na história do jornalismo. Para ele, novo é "o uso massivo de computadores (robôs) que replicam a mesma notícia falsa e pressionam pessoas com centenas de milhares de posts buscando massacrar opiniões adversas" 2 .

A digitalização da comunicação e a ação dos algoritmos na organização da dieta midiática contemporânea perpassa boa parte dos ensaios, nesta análise divididos em três grandes blocos, a fim de sublinhar as interconexões que vão se apresentando no decorrer da leitura. O primeiro bloco versa sobre a notícia e suas falsificações no passado e no presente; o segundo conjunto reúne textos que falam do impacto das fraudes noticiosas nos estados democráticos; e o último eixo temático discute o discurso noticioso na desordem informacional.

\section{A notícia e suas falsificações}

Com boa dose de crítica à imprensa tradicional, o pesquisador da Pontifícia Universidade Católica do Rio Grande do Sul (PUCRS) Juremir Machado abre o primeiro grupo de ensaios questionando se as fake news "[...] poderiam ser vistas como falsificações verdadeiras contra as falsificações dissimuladas dos veículos de comunicação com suas omissões, seleções, enquadramentos, hierarquias de edição e até mentiras deslavadas?”3.

Carla Baptista, da Universidade Nova de Lisboa, segue nessa linha com outra pergunta: quem estragou as notícias?4. Apoiada em Habermas e as mudanças estruturais da esfera pública, a pesquisadora portuguesa elabora uma interessante reflexão sobre a 'esfera pública disruptiva', na qual a vida comunicativa coletiva não mais é pautada pela vitória dos melhores argumentos; sobretudo, é fortemente influenciada pela publicidade manipulativa. Posicionando a desinformação no contexto da crise mais geral do jornalismo provocada pelas dinâmicas da digitalização, Baptista diz que "a Internet não organiza a discussão no sentido de permitir 'comunicar através das diferenças"”. Ao contrário, a esfera pública está repleta de 'bolhas de pósverdades' permeáveis apenas ao que confirma convicções.

Como se continuasse o raciocínio de Baptista, o texto assinado por Inês Amaral e Sofia José Santos aborda os algoritmos e as redes sociais como novos atores no processo de gatekeeping, até então executado por jornalistas enquanto profissionais com 'autoridade social' para tal mediação $0^{5}$. É interessante a menção ao conceito de 'datificação', ou seja, o uso de big data para transformar ações sociais em dados quantitativos no intuito de tornar os processos de seleção e filtragem menos subjetivos ${ }^{5}$ o que claramente favoreceu a 
formação das bolhas de pós-verdades citadas por Baptista ${ }^{4}$ e notáveis em debates públicos e processos eleitorais recentes nos diferentes países.

Fechando o primeiro bloco, Muniz Sodré conduz sua reflexão desde os factoides até as fake news. Discorre acerca do sensacionalismo, dos fait divers, do 'publicismo' no século XIX, quando Balzac dizia que os jornais não mais serviam para esclarecer, mas para bajular opiniões ${ }^{6}$, da notícia como commodity no século XX e suas relações com novidade e emoções represadas, componentes afetivos que, para Sodré, fazem parte da estrutura das fake news: "A novidade mobiliza inicialmente a atenção do interlocutor, suscitando uma espécie de alerta. A emoção represada, em que atuam fortemente resquícios do imaginário coletivo, leva à aceitação acrítica do fato embutido na novidade e epidemicamente acelerado pela velocidade circulatória das redes. O efeito é análogo ao da contaminação viral. E havendo gratificação afetiva ou autossatisfação narcísica, desaparece a antinomia entre verdade e mentira" ${ }^{\text {. }}$

\section{As fraudes noticiosas nos estados democráticos}

Conjunto mais curto, porém mais denso de textos, com aporte em pensadores da democracia, da comunicação política e da sociologia, o segundo bloco temático da coletânea versa sobre o impacto das fraudes noticiosas nas sociedades democráticas ao longo da história. São textos que ajudam a dimensionar o fenômeno do ponto de vista sócio e geopolítico.

Alexandre Franco de Sá, da Universidade de Coimbra, vai até Sócrates, passando por Hobbes e Rousseau para discorrer sobre justiça, soberania e verdade. Na soberania, encontra-se o que ele chama no texto de "préverdade", uma verdade dada pelo poder soberano. Na democracia moderna, ao contrário, "para Rousseau, o próprio povo é soberano: é na vontade geral do povo, e não na tirania de uma qualquer vontade particular, que se fundam justiça e verdade"7. Com Roberspierre, Marx e Engels, Lippmann, Nietzsche e Arendt, o pesquisador português percorre a história do século XX e os diferentes modos de pensar o Estado, os fatos e as opiniões, até chegar ao conceito de 'estado terapêutico', já na era da 'pós-verdade': “Sucedâneo pós-moderno do Estado totalitário, o Estado terapêutico assume a tarefa não propriamente de reescrever a história, mas de usar o aparelho mediático para cultivar na população uma maneira de pensar e sentir que a corrija a posteriori. Trata-se, portanto, de conceber o passado como um conjunto de violências a banir e de culpas a expiar numa terapia infinita pela qual, mediante o cultivo ininterrupto de uma sensibilidade adequada, a sociedade, o mundo e os seres humanos se possam, finalmente, tornar melhores"”.

Já Helder Prior oferece um panorama do populismo perante a crise da democracia representativa contemporânea. Embora recorra às origens do populismo clássico, com diferentes matizes na Rússia e nos Estados Unidos no século XIX, é na análise do uso de "mecanismos de fraude" perante a emergência de novas formas de mediação ${ }^{8}$ que ficam evidentes certas permanências discursivas. A narrativa "pelo povo e contra os corruptos", antielite ou antissistema, encontra eco em todos os casos recentes em que a extrema-direita ascendeu ao redor do mundo, inclusive no Brasil. "Recorrendo à exploração de patologias ou anomias sociais, como a corrupção política, o desemprego, a criminalidade e outros temas que provocam insegurança e sensação de risco na população, os novos movimentos populistas promovem, geralmente, uma campanha para salvar o país ou para fomentar uma profunda regeneração das instituições políticas".

Não é difícil associar tais anomias à campanha vencedora de Jair Bolsonaro, seja por um apelo armamentista do então candidato, que prometeu facilitar o acesso a armas para o 'cidadão de bem' e endurecer a ação policial contra criminosos, seja pela promessa de impulsionar a economia, desburocratizar o empreendedorismo e gerar mais empregos, seja ainda pela tônica antipetista fortemente associada à corrupção, graças à Operação Lava-Jato, liderada pelo então juiz Sergio Moro, que depois virou ministro no governo eleito. Bolsonaro se forjou, no discurso, não como um presidente, mas como um 'salvador da 
Pátria'. Tal discurso pode ser altamente beneficiado por uma 'emoção represada', que leva à aceitação acrítica do que parece novidade, parafraseando Sodré6.

\section{O discurso noticioso e a desordem informacional}

O último conjunto de textos da coletânea versa sobre a linguagem das notícias e busca dimensionar a participação do jornalismo na desordem informacional contemporânea. Fernando Zamith, da Universidade do Porto, enumera situações em que o ciberjornalismo "se contenta com pouco", de modo a favorecer o processo de desinformação. Vem deste artigo a mais original, didática e talvez sarcástica definição de "pósverdade", como algo que está "para lá da verdade", mas não pelo prefixo 'pós', e sim pelo substantivo 'pó'.

O autor propõe uma discussão do fenômeno contemporâneo a partir dos 'pós de verdade', espalhados inclusive pelo jornalismo. É poeira, sujeira, 'são restos sem valor' de verdade que contaminam o discurso público - muitos dos quais insistimos em tratar como notícias apenas por estarem sob o guarda-chuva de uma organização jornalística reconhecida. A publicação apressada sem confirmação, os títulos 'caça-clique' (clickbait), o uso abusivo de fontes não identificadas, a reprodução acrítica e sem contexto de declarações (jornalismo declaratório) e a publicação de conteúdos patrocinados ao lado de notícias são algumas das práticas citadas por Zamith ${ }^{9}$. Seria uma resposta possível ao questionamento de Juremir Machado ${ }^{3}$ no primeiro capítulo da coletânea?

Também com sagacidade altamentefundamentada, Luis Antônio Umbelino, da Universidade de Coimbra, descreve três figuras-tipo que tendem a colonizar a "linguagem do espaço público noticiada"10. $\mathrm{O}$ 'opinador emotivo' representa a opinião espontânea. O 'perito soberbo' é o que pretende ensinar "especializadamente a educar crianças, a ser amáveis e empáticos, a ser felizes e seguros de si, a ser saudáveis e bonitos, a fazer amor, a influenciar os outros, a liderar, a arranjar amigos, a seduzir, a sentir-se bem na própria pele, a comer como deve ser, a competir, a ter sucesso [...]" ${ }^{\text {”o }}$. E o 'ideólogo de grupo' é o que afirma um ponto de vista sobre os assuntos como uma forma de 'defesa' ideológica, sob forte influência da simplificação do conhecimento e empobrecimento das visões de mundo. Facilmente você associa tais figuras-tipo a certos tipos no seu Twitter ou WhatsApp.

Ao analisar a circulação de sentidos nas eleições brasileiras de 2018, Antônio Fausto Neto, da Universidade do Vale do Rio dos Sinos (Unisinos), afirma, taxativo, ser "impossível banir as fake news do sistema social"11, e abre caminho para outra discussão: "as ações que se disseminam para combatê-las são análogas àquelas que são feitas em sistemas hidráulicos nos quais os canos apresentam vazamentos, recebendo reparos emergenciais e provisórios, uma vez que as causas são de natureza estrutural”11.

Soou-me curiosa a analogia utilizada pelo pesquisador, à qual também eu já havia recorrido ao descrever as mudanças estruturais do jornalismo diante da desordem informacional: "Há muitos indícios, portanto, de que o sistema de jornais já não é mais o mesmo, mas não há consenso sobre as condições de sua estrutura. Na sua casa, por exemplo, quando a torneira do banheiro está pingando, você identifica que aquele dispositivo está com problema. Você troca a torneira e ela para de pingar. Mas de repente a torneira da cozinha também começa a pingar. Dias depois, a do pátio. Provavelmente, o sistema de encanamento de sua casa esteja colapsado. Não basta fazer adaptações nos dispositivos. Você tem um problema de estrutura para enfrentar"12.

A coincidência metafórica chama atenção, pois Fausto Neto ${ }^{11}$ assume haver mudanças estruturais nas lógicas de mediação discursiva contemporâneas, o que, a meu ver, implica mudanças também no jornalismo. Parte significativa dessas mudanças se deve à predominância de dispositivos móveis nos processos midiáticos, ponto central do artigo de Egle Müller Spinelli e Daniela Osvaldo Ramos ${ }^{13}$, que se propõem a analisar como empresas de tecnologia, governos, organizações de mídia, sociedade civil, ministérios de Educação e fundações de financiamento responderam à desordem informacional, tendo como principal referência o relatório Information Disorder ${ }^{14}$, encomendado pelo Conselho Europeu. Cruzando dados de diferentes fontes, as pesquisadoras oferecem uma leitura contextualizada do cenário brasileiro da desordem 
informacional, passando pelo acesso massivo à internet via celular, com planos de dados precários, altos níveis de analfabetismo funcional e fraca literacia midiática. Combinados, esses fatores suplantam reparos paliativos que vêm sendo implementados no sistema de mídia ao longo do tempo, incluindo esforços de fact-checking empreendidos no Brasil no último período eleitoral.

Tais esforços ganham destaque no artigo de Thaïs Mendonça Jorge, da Universidade de Brasília, não pela criação de projetos desse tipo, mas pelo discurso das organizações jornalísticas sobre os projetos: um discurso que destaca a relação entre jornalismo e verdade, por parte de uma imprensa com a credibilidade corroída. A pesquisadora também investiga como jornalistas brasileiros veem o fenômeno da desordem informacional e a participação do jornalismo nesse processo, a partir de uma enquete respondida por 210 jornalistas e professores de jornalismo ${ }^{15}$. As respostas oscilam entre a reafirmação de princípios normativos de verdade e objetividade - 'se é fake, não é news' - e a crítica a procedimentos contrários à prática jornalística "de excelência", mais ou menos como os "pós de verdade" levantados por Zamith9 em seu artigo na mesma coletânea.

O texto que encerra a obra é uma verdadeira pérola para pensar não só o jornalismo, mas a construção do conhecimento na sociedade contemporânea. Sandra Marinho, da Universidade do Minho, defende as ciências humanas e sociais como instrumento de fact-checking. "Para lá dos dispositivos, cada vez mais tecnologicamente sofisticados, de detecção de informação falsa, a primeira linha de verificação para um jornalista é aquilo que ele já sabe. É o conhecimento prévio sobre história, arte, economia, filosofia, estatística, geografia ou sociologia que o faz suspeitar da veracidade de um dado, de uma afirmação"16. Ao estudar a prática de fact-checking, também procurei destacar o papel de "contextualizar temas em discussão, não necessariamente atribuindo selos e escalas de veracidade"12 como o principal trunfo da verificação.

Difícil é defender esse domínio quando saberes dessa ordem são alvo de questionamento, o que de certa forma é institucionalizado em mudanças curriculares que priorizam certos conhecimentos de cunho técnico ou tecnológico. Ao pontuar que o estudo das ciências humanas e sociais deve perpassar todos os cursos superiores, mas principalmente o jornalismo, Marinho critica mudanças recentes nos currículos acadêmicos, algo que pode ser perfeitamente espelhado na realidade brasileira desde a mudança das diretrizes curriculares do curso de jornalismo, em 2013. Seria possível ainda adicionar as novas diretrizes para o ensino médio brasileiro, em fase de implementação, também tirando peso das ciências humanas e sociais. Se a defesa de uma alfabetização midiática tem sido unânime entre estudiosos do tema, e boa parte das peças de desinformação estão contaminadas por simplificações e visões equivocadas de fatos históricos e achados científicos, é de se pensar se o que se quer é mesmo estimular uma cultura de verificação ou se as 'pós-verdades' são mais convenientes.

Diante de tantas provocações, restam claras as inter-relações existentes entre o conjunto completo de textos da coletânea, abrindo um olhar alargado o bastante do fenômeno da desinformação para que se possa dimensionar a complexidade do tempo presente, mas ainda insuficiente para nos fazer compreendêlo de forma plena. Pela diversidade de pontos de vista e pelo gabarito dos articulistas convidados, a obra organizada por Figueira e Santos candidata-se a leitura obrigatória pelos lusófonos que pretendem estudar a desordem informacional. 


\section{Referências}

1. Figueira J., Santos S, organizadores. As fake news e a nova ordem (des)informativa na era da pósverdade. Coimbra: Coimbra University Press; 2019. Introdução, História institucional e a reescrita permanente das estórias; p. 7-16.

2. Marcondes Filho C. Apresentação, Fake news: o buraco é muito mais embaixo. In: Figueira J, Santos S, organizadores. As fake news e a nova ordem (des)informativa na era da pós-verdade. Coimbra: Coimbra University Press; 2019. p. 17-32.

3. Machado J. Fake News, a novidade das velhas falsificações. In: Figueira J, Santos S, organizadores. As fake news e a nova ordem (des)informativa na era da pós-verdade. Coimbra: Coimbra University Press; 2019. p. 33-46.

4. Baptista C. Digitalização, desinformação e notícias falsas: uma perspectiva histórica. In: Figueira J, Santos S, organizadores. As fake news e a nova ordem (des)informativa na era da pós-verdade. Coimbra: Coimbra University Press; 2019. p. 47-62.

5. Amaral I, Sofia JS. Algoritmos e redes sociais: a propagação de fake news na era da pós-verdade. In: Figueira J, Santos S, organizadores. As fake news e a nova ordem (des)informativa na era da pósverdade. Coimbra: Coimbra University Press; 2019. p. 63-86.

6. Sodré M. O facto falso: do factoide às fake news. In: Figueira J, Santos $\mathrm{S}$, organizadores. As fake news e a nova ordem (des)informativa na era da pós-verdade. Coimbra: Coimbra University Press; 2019. p. $87-100$.

7. Sá AF. Pré-verdade, verdade e pós-verdade: um percurso rumo à política contemporânea. In: Figueira J, Santos S, organizadores. As fake news e a nova ordem (des)informativa na era da pós-verdade. Coimbra: Coimbra University Press; 2019. p. 101-22.

8. Prior H. Em nome do povo: o populismo e o novo ecossistema mediático. In: Figueira J, Santos S, organizadores. As fake news e a nova ordem (des)informativa na era da pós-verdade. Coimbra: Coimbra University Press; 2019. p. 123-47.

9. Zamith F. Pós de verdade: quando o (ciber)jornalismo se contenta com pouco. In: Figueira J, Santos S, organizadores. As fake news e a nova ordem (des)informativa na era da pós-verdade. Coimbra: Coimbra University Press; 2019. p. 147-66.

10. Umbelino LA. Para acabar de vez com as boas notícias. Elogio das pequenas coerências e da justa complexidade. In: Figueira J, Santos S, organizadores. As fake news e a nova ordem (des)informativa na era da pós-verdade. Coimbra: Coimbra University Press; 2019. p. 167-76.

11. Fausto Neto A. Fake news e a circulação de sentidos nas eleições presidenciais brasileiras: 2018. In: Figueira J, Santos S, organizadores. As fake news e a nova ordem (des)informativa na era da pósverdade. Coimbra: Coimbra University Press; 2019. p. 177-98.

12. Seibt T. Jornalismo de verificação como tipo ideal: a prática de fact-checking no Brasil [tese]. Porto Alegre: Universidade Federal do Rio Grande do Sul; 2019.

13. Spinelli EM, Ramos DO. Desordem informacional no ecossistema digital das eleições brasileiras de 2018. In: Figueira J, Santos S, organizadores. As fake news e a nova ordem (des)informativa na era da pósverdade. Coimbra: Coimbra University Press; 2019. p. 199-222.

14. Wardle C., Derakhashan H. Information disorder: toward an interdisciplinary framework for research and policy making. Strasbourg: Council of Europe; 2017. Report DGI(2017)09.

15. Jorge TM. Notícia versus fake news. A explosão discursiva das informações falsas e o mundo dos jornalistas. In: Figueira J, Santos S, organizadores. As fake news e a nova ordem (des)informativa na era da pós-verdade. Coimbra: Coimbra University Press; 2019. p. 223-46.

16. Marinho S. As fake news dos jornalistas: a formação em Ciências Sociais e Humanas como estratégia de verificação. In: Figueira J., Santos, S., organizadores. As fake news e a nova ordem (des)informativa na era da pós-verdade. Coimbra: Coimbra University Press; 2019. p. 247-76. 